\title{
Os caminhos dialéticos do envelhecimento e sua relação com a educação física contemporânea
}

The dialectical ways of aging and their relationship with contemporary physical education

Resumo

Este artigo pretende discutir criticamente as concepções e ideias construídas acerca do processo de envelhecimento na sociedade, no intuito de demarcar a velhice não apenas como espaço de perdas e limitações, mas sobretudo como um estágio de desenvolvimento aberto a novas possibilidades de inserção social. Para tanto, se faz premente que a sociedade oferte a essa população meios favoráveis à prática de múltiplas atividades, dentre elas, as atividades físicas, fundamentais para a melhoria na qualidade de vida durante o processo de envelhecimento. $O$ texto se arquiteta mediante um processo de revisão e atualização de literatura, utilizando como bases teóricas obras da Sociologia, Psicologia, Medicina, Gerontologia e Educação Física, de modo a promover um diálogo interdisciplinar entre as referidas áreas, buscando demarcar o envelhecimento como um processo multifatorial, portanto, se estabelecendo para além de uma redução biológica. Exatamente neste sentido, acreditamos no potencial da Educação Física com a população idosa, qual seja: o de uma área que realize nexos conectivos entre o biológico e o social e entenda o humano em sua constituição histórico-cultural.

\section{Abstract}

This paper aims to critically discuss the concepts and ideas built on the aging process in society, regarding ageing not only as space of limitations and losses, but mainly as a stage of development to open new possibilities for social inclusion. Society must favor this population with several activities, such as physical activity, fundamental to improve the quality of life during the aging process. This text is built in a process of literature review and updating, employing theoretical works on Sociology, Psychology, Medicine, Gerontology and Physical Education, whose aim is to promote an interdisciplinary dialogue between those

Curso de Pós-graduação em Educação Especial (Educação do Indivíduo Especial). Centro de Ciências Biológicas e da Saúde, Departamento de Educação Física, Universidade Federal de São Carlos. São Carlos, SP, Brasil

Correspondência / Correspondence

Gustavo Martins Piccolo

Alameda Estevo, 330 - Centro

14813-000 - Gavião Peixoto, SP, Brasil.

E-mail: gupiccolo@yahoo.com.br
Gustavo Martins Piccolo?

Palavras-chave: Qualidade de vida. Envelhecimento. Atividade física. 
areas and considering aging as a multi-factorial process, thus establishing itself in addition to a biological reduction. So we believe in the potential of Physical Education for the elderly population, namely, that of an area to conduct connective links between biological and social factors and understand the human in its historical and cultural formation.
Key words: Quality of Life. Aging. Motor Activity.

\section{INTRODUÇÃO}

O envelhecimento deve ser entendido para além de uma questão meramente biológica, pois em sua constituição fazem parte também elementos sociais, culturais, políticos e ideológicos. Por isso, falar em envelhecimento significa tecer considerações sobre um fenômeno que é uma representação social, entendendo esta como "[...] um conjunto de conceitos, afirmações e explicações originadas na vida cotidiana, no curso de comunicações inter-individuais e ao longo da história."1

Isto posto, não consideramos neste trabalho a categoria envelhecimento como um conceito autoexplicativo. Definir a velhice é uma questão social, coletiva e profundamente complexa, pois ser velho contemporaneamente pode não possuir relação com o "ser velho" na Antiguidade ou na Idade Média, no Ocidente ou no Oriente. Assim, na França do século XIX, a palavra "velhice" era utilizada para caracterizar as pessoas que não podiam obter seu próprio sustento, não possuindo relação direta com a cronologia etária, fenômeno distinto, mas não em sua totalidade, ao que percebemos nos dias atuais.

Ser velho em uma sociedade de castas ou em uma comunidade baseada em laços fraternos também não é o mesmo que ser velho nas sociedades capitalistas contemporâneas, que apesar de não tratarem a velhice da mesma forma, em geral destinam poucos lugares para sua valorização. A evolução da ciência capitalista não culminou com a valorização da população idosa, muito pelo contrário, pois sua tendência consiste na negação de seus saberes e práticas, isolando-a das relações sociais - que no caso dos seres humanos, representam a base de sua constituição. ${ }^{2}$ Devido a esta estrutura social injusta e discriminatória, urge arquitetarmos um conjunto de medidas políticas, educacionais e filosóficas que transformem o não-lugar fornecido aos idosos pelo capitalismo hodierno em um contexto no qual as diferenças passem a ser valorizadas tanto em aspectos legais como práticos.

Coerentemente, não podemos esquecer que nos dias atuais a categoria "velhice" tem sido sistematicamente oprimida e desvalorizada quanto a suas potencialidades interventivas sobre a natureza. ${ }^{3}$ Ser velho no capitalismo significa literalmente estar ultrapassado, pois, nesse universo, os anos esvaídos, muito mais do que produzirem experiência social, engendram desatualização e anacronismos vistos como mazelas a sociedade.

Contudo, como toda questão social carrega a contradição dialética em sua constituição, nem sempre o processo de envelhecimento na sociedade capitalista é necessariamente cercado por angústias intransponíveis, pois se muitos a consideram como uma etapa na vida em que o homem se transforma em um ser obsoleto, para outros a velhice pode ser uma das melhores etapas da vida. Quando pensada em termos de possibilidade e não limitação, a velhice pode ser uma etapa propícia à reflexão do já vivido, à transformação de posturas, conceitos e valores sociais; à assunção de outra relação perante a realidade circundante; à reconstrução de nossa identidade e à própria forma com que nos relacionamos com a diferença.

Acreditamos ser este o pano de fundo do conceito de terceira idade, termo contemporâneo associado aos aspectos positivos do envelhecer, tais como as novas possibilidades de aprendizagem, vínculos afetivos, práticas de lazer e satisfação 
pessoal. Esse fato estabelece consequentemente uma contraposição à ideia da velhice como momento de calmaria e reminiscências de todos os tipos. Desde que esta nova conjuntura histórica seja entendida como produto de construções sociais vindouras e não apenas de engajamentos individuais, pensamos ser positivo o conceito de terceira idade como gerador de um novo campo de relações sociais. Ainda que aqui não entremos no mérito da discussão da cronologia etária que tal conceito carrega e no fenômeno da mercantilizarão da velhice tão a gosto da indústria cultural que a tudo transforma em valor de troca e objeto de venda, inclusive, nossos próprios gostos.

De acordo com esses pressupostos, a velhice é encarada aqui como uma construção histórica, uma vez que a posição social ocupada pelos idosos não são as mesmas em distintos países, regimes sociais ou tempos cronológicos. As concepções e práticas que temos sobre os idosos podem e devem ser transformadas, objetivando que todos possam ser encarados não apenas como participantes, mas também atores e autores da sociedade da qual fazem parte. Colocado estes apontamentos, pretendemos discutir as concepções que tratam a velhice como se esta fosse um estágio preparatório para a morte, contrapondo suas problemáticas com argumentos sociológicos e filosóficos críticos quanto às posições naturalistas.

\section{A LINGUAGEM DA NEGATIVIDADE}

$\mathrm{O}$ século XX engendrou uma verdadeira revolução no que tange à longevidade da espécie humana. Somente durante este centenário, a vida humana incrementou aproximadamente 30 anos ao seu período de existência, logo, o envelhecimento é um fenômeno global e generalizado; não é questão retórica, mas científica e epistemológica. ${ }^{4}$

Isto posto, é fenômeno mais do que "natural" a população de idosos, seja em números absolutos ou relativos, apresentar um significativo crescimento, produto este fruto de melhores condições sociais, políticas, científicas e médicas.
Destarte, a velhice, ainda que capitaneada pelos interesses mercantis de um capitalismo polarizante, torna-se matéria de interesse público constantemente veiculado nas mais diversas mídias, inclusive ganhando representatividade em discursos acadêmicos.

O crescimento exponencial da população idosa, coadunado com a falta de preparo material e espiritual por parte da sociedade ao fenômeno do envelhecimento, implica a criação de novos mecanismos e demandas históricas que enfrentem o desafio de transformar a velhice numa etapa de inserção mais ampla na sociedade da qual se participa, estimulando, por conseguinte, a prática de vivências múltiplas e diversificadas. Todavia, a consecução deste anseio - aliás, seu próprio estabelecimento - depende da própria forma como encaramos a velhice, já que esta é tanto um fenômeno biológico como social e cultural.

Biologicamente, o envelhecimento pode ser delineado como um estágio de degeneração do organismo, implicando diminuição na capacidade de sobreviver. ${ }^{5} \mathrm{Na}$ maioria das vezes, esse estágio é demarcado de forma cronológica, mesmo sabendo-se que esta variável não possui bom grau de fidedignidade científica, uma vez que os anos são vividos de distinta maneira por cada ser humano em particular. Assim, apesar de a idade ser o critério mais utilizado na grande maioria das vezes para determinar o estágio de desenvolvimento de cada ser humano, ela se mostra extremamente falha quando as análises acadêmicas transcendem um plano exclusivamente biológico pelo prisma mediativo de variáveis históricas, culturais e sociais.

No interstício dessa encruzilhada, a análise científica sobre o envelhecimento parece adentrar um atoleiro do qual não consegue sair, tal qual aquele descrito por Vygotsky ${ }^{6}$ em relação à Psicologia nos princípios do século XX. Uma possível resposta para a saída deste lamaçal epistemológico, inevitavelmente materializado na dificuldade de quantificar o nível de envelhecimento de uma pessoa, reside no estabelecimento de fronteiras entre a saúde e a 
doença na velhice e, por fim, reconfigurar todo o campo de relações no qual esta população é direta ou indiretamente envolvida. ${ }^{7} \mathrm{Ou}$ seja, trata-se aqui de separar o normal do patológico em um viés que não entenda o biológico e o social como opostos excludentes, redefinindo conceitos estereotipados que atravancam nossa compreensão sobre o próprio fenômeno do desenvolvimento humano, do qual a velhice é parte integrante.

Por uma questão de coerência, tanto filosófica como prática, não podemos coadunar com o pressuposto de que a juventude signifique por si só saúde e o envelhecimento a simbologia de sua decadência devido ao desgaste do organismo. ${ }^{8}$ Cada ser humano é único, irrepetível e histórico, por isso toda generalização sobre fenômenos sociais tende a entrincheirar-se em concepções insustentáveis. Inadvertidamente, muitas destas concepções, principalmente quando são veiculadas pelo estrato dominante da sociedade, podem se difundir e propagar como verdades absolutas e incontestes, inclusive dando origem a trabalhos que busquem sua comprovação e justifiquem (ou melhor, encubram) seus preconceitos e dogmas.

A tentativa de demonstrar a velhice como um período somente de declínio e perdas inicia-se academicamente a partir da institucionalização biológica da idade proposta por Bichat, que viu na deterioração dos tecidos ocorrida durante o passar dos anos o esgotamento da própria vida em questão. Desde então, o envelhecimento corpóreo passa a ser encarado como uma espécie de declínio vital rumo à morte. ${ }^{9}$ Aqui, envelhecer significa morrer, mesmo que gradativamente, como se o envelhecimento fosse uma doença progressiva, engendrando apenas reduções funcionais e motoras - enfim, um período de perdas, seja de cabelos, unhas, pelos, dentes e até da própria vida.

Tal concepção de envelhecimento formou a base teórica sobre a qual surgiu a geriatria no início do século XX, cuja gênese buscava se transformar em algo parecido do que era a pediatria para as crianças. ${ }^{7,10}$ Nesse contexto, a questão da saúde foi vilipendiada analiticamente nos processos de envelhecimento, sendo que sua repercussão ainda se mostra bastante presente nas áreas que estudam temáticas relativas ao envelhecimento, pois se é fato que a linguagem não reflete como espelho as práticas sociais, também o é que ela influencia mediatamente sua edificação e o espaço/forma no qual deve ser realizada. Como crítica à linguagem estereotipada, que alavanca práticas segregacionistas aos idosos, é fundamental que edifiquemos um novo significado para a própria categoria de velhice, não mais ancorada em pressupostos negativos e estáticos, como se o envelhecimento retirasse os elementos da humanidade constituinte de cada sujeito em particular.

\section{NOTAS SOBRE 0 ENVELHECIMENTO}

Em primeiro lugar, é importante assinalar que o envelhecimento é um processo universal do ser vivo, acarretando transformações morfológicas e funcionais na medida de seu aparecimento. Em tese, apesar de nem sempre este se concretizar devido a causas que não cabem citar aqui, envelhecer é tão natural quanto nascer ou morrer. Mas, no caso humano, os produtos do envelhecimento recebem cortes outros que não apenas os biológicos.

A velhice humana provoca tanto alterações nas condições anátomo-fisiológicas dos mais diversos sujeitos, assim como modifica as formas com que estes se inserem na sociedade. Neste ponto situamse os elementos mais profícuos em uma análise social sobre o fenômeno do envelhecer, pois não existe uma única forma de envelhecer, pois esta varia em distintos gêneros, etnias, classes sociais e culturas. ${ }^{11}$ Devido a tais características, o envelhecimento pode ser considerado um processo composto por múltiplos fatores, dos quais apenas $30 \%$ possuem significativa relação com os domínios genéticos. A porcentagem restante é construída socialmente, por isso a necessidade de estudos que se dirijam a outras áreas que não apenas as biológicas. ${ }^{12}$

Apesar desta gama de fatores, apenas em meados da década de 70 do século XX as questões relativas ao envelhecimento começaram a ser 
estudadas sob um prisma sociológico, tendo como estopim engendrador o estudo de Simone de Beauvoir ${ }^{13}$, o qual discute o envelhecimento a partir do papel e local que a sociedade capitalista ocidental destina aos idosos. Em tal escopo teórico, a velhice passa a ser vista como uma categoria em constante formulação, sendo adjetivada negativamente na estrutura social capitalista devido a sua suposta sinonímia com a perda funcional da força de trabalho, que materializa o leitimotiv sui generis das relações sociais erigidas sob a égide do capital.

Adjudicados por este complexo segregacionista guindado sob a batuta do capital, o idoso ainda convive com perdas familiares, doenças, a solidão, o descaso da sociedade para com ele e as próprias capacidades funcionais naturalmente reduzidas. $\mathrm{Ou}$ seja, no contexto apresentado acima, envelhecer parece ser apenas um caminho para a morte. Por estas características, o envelhecimento pode ser considerado um contex to frágil, de risco e propenso à degradação social do idoso. Entretanto, nem sempre essa situação adversa produz comportamentos negativos; muito pelo contrário, pois é digno de nota o fato de nosso próprio contexto histórico demonstrar que, mesmo contra todas as tendências de desvalorização da velhice, muitos idosos superam dialeticamente os entraves colocados em seu caminho, arquitetando uma atitude social denominada de resiliência. ${ }^{14}$

A resiliência, grosso modo, sintetiza a capacidade de adaptação do sujeito em face de situações intrinsecamente adversas, na qual todos os fatores o direcionam para o insucesso e seu produto contraria as expectativas iniciais. Destarte, a resiliência pode ser encarada como um complexo processo dialético resultante da interação entre o ser humano (psíquica, gnosiológica e corporal) e a sociedade da qual faz parte.

Posto isso, ainda que com todas as dificuldades encontradas cotidianamente, nem todos os idosos encaram a velhice apenas como momento de perda, pois a forma como determinado sujeito encara a velhice é, em grande parte, resultante do conjunto de suas experiências passadas e da maneira como sua personalidade foi se formando no decorrer de sua vida. Esse fato nos coloca a importância de arquitetarmos desde nossa infância uma distinta interpretação quanto ao fenômeno e potencialidades do envelhecimento.

Coerentemente com esses pressupostos, se é fato que a ciência conseguiu aumentar a longevidade humana a níveis nunca vistos, também o é que a maioria das sociedades atuais ainda não aprendeu a tratar proficuamente a questão do envelhecimento - tratamento não no sentido medicamentoso, pois seu significado reside em propiciar para sua população não apenas mais anos em suas vidas, mas que essas vidas se desenvolvam plenamente e em todas suas potencialidades e riquezas. Esta é ainda a grande questão a ser resolvida hodiernamente, passando pelo campo de reformas políticas, educacionais, culturais e da criação de espaços não segregados para os idosos na sociedade.

Neste ponto, entendemos que algumas propostas elaboradas pela Educação Física nãoescolar que visam à prática de esportes/atividades físicas pela população idosa única e exclusivamente pela melhoria da saúde estão inextricavelmente fadadas ao fracasso, na medida em que transferem para o exercício físico um poder regenerativo holístico cuja materialidade não se coaduna em sua prática cotidiana.

Em virtude destes elementos, é necessário romper com a concepção da atividade física como a única resposta que pode ser dada à complexa questão do envelhecer na sociedade, assim como relativizar as pesquisas nesta mesma área acadêmica, voltadas para o aprimoramento de habilidades motoras (pois aqui o objeto de estudo se torna mais a atividade do que o próprio sujeito). A metodologia espelhada em um positivismo acéfalo se esquece de considerar como fator importante a qualidade de vida das pessoas idosas, o significado que assume as atividades físicas em suas vidas e o próprio objetivo que buscam ao realizá-las. Às vezes não são os centímetros conquistados que realmente importam em um programa de atividades físicas, mas a forma como esse centímetro foi ganho, se com risos e alegria ou mediante um processo não tão prazeroso como poderia vir a ser. 


\section{CONTRIBUIÇÕES DA EDUCAÇÃO FÍSICA}

São múltiplas as contribuições que a Educação Física e as atividades físicas podem produzir direta ou indiretamente sobre a população idosa. As contribuições diretas se relacionam àquelas no qual a população de idosos passa a fazer parte de um grupo regular de atividades físicas. As indiretas podem incidir tanto no processo educacional desde a pré-escola, com a disciplina Educação Física redimensionando as questões ligadas ao processo de envelhecer na sociedade, até no plano político, como forma de luta conjunta da sociedade para implementar medidas legais que garantam condições materiais e meios propícios ao pleno desenvolvimento da população em questão.

O envelhecimento traz consigo demandas específicas para a produção de uma vida plena e rica em vivências culturais, as quais passam pelas esferas sociais, culturais, políticas, científicas, filosóficas, artísticas, laboriosas e lúdicas. De nada adianta ter um maior tempo livre disponível se a sociedade não oferece condições para que esse tempo possa ser objetivado com diversas atividades.

Por isso, não podemos nos esquecer de que “ 0 tempo é ambivalente:pode ser benéfico ou prejudicial, pois, se o tempo livre não for preenchido com atividades significativas para a pessoa, pode se tornar uma carga. ${ }^{15}$ Destarte, o maior tempo disponível na velhice deve ser ocupado com atividades significativas do ponto de vista funcional e sócio-comunicativo, que façam sentido à materialização de sua prática. Neste universo, a Educação Física pode encontrar grande acolhida, tanto em termos funcionais como atitudinais, pois ela trata de uma área cuja temática principal reside na produção de corpos em movimento, movimentos não apenas no sentido de deslocamento no espaço, mas de transformar-se, ser diferente, relacionar-se de forma ampla com a diversidade das culturas humanas. Analisemos esta questão de maneira mais detalhada.

Hodiernamente, é inegável o fato de o sedentarismo ter se tornado um problema de saúde pública, cujo índice aumenta exponencialmente na população idosa. ${ }^{16}$ Essa conjuntura tende a dificultar sobremaneira a inserção do idoso na sociedade, o qual acaba por assumir, embora isso não seja uma regra, comportamentos de retração e isolamento social, facilitadores do aparecimento de enfermidades psicológicas como a depressão e outros males característicos das sociedades contemporâneas.

Por essa razão, as atividades físicas se tornam mecanismos fundamentais para um trabalho social com a população idosa, objetivando a melhoria de suas capacidades motoras, funcionais e sociais consideradas globalmente. Em direção à produção dos novos saberes, a Educação Física deve se situar como campo de intervenções sobre a população idosa. Claro que não se trata de uma tarefa fácil, pois sua incorporação necessita da materialização dos princípios da inclusão de forma radical (por sua raiz epistemológica), pois abrange um amplo projeto interventivo voltado para os idosos, não no sentido de exclusividade dessa população, mas porque em sua essência se dirige a todo e qualquer ser humano.

Como pressuposto basilar, a Educação Física deve perceber que a relação entre saúde e qualidade de vida está inequivocamente ancorada na construção de ambientes favoráveis a máximas relações interpessoais, já que não podemos entender por saúde simplesmente a ausência de doença, pois englobar também o bem-estar físico, psicológico e mental. ${ }^{17} \mathrm{Em}$ vista disso, nossa premissa básica é que não é o envelhecimento que proporciona um grande nível de sedentarismo, mas seu inverso, cuja superação tem nas atividades físicas seu principal agente. ${ }^{18}$

Contudo, mesmo considerando as vantagens obtidas pela prática do exercício físico aos idosos, estes ainda tendem a se mostrar resistentes a sua prática, o que se justifica pelo próprio rótulo de incapacidade colocado sobre esta população mediante diversos estereótipos pejorativos e também em virtude de uma falsa crença cotidiana de que a realização de atividades físicas representa uma prática dolorosa, o que certamente não corresponde à realidade dessas atividades, sobretudo quando bem orientadas. 
Este fato demonstra que, por mais que os idosos clamem por uma melhor saúde, não necessariamente se sentem motivados a se inserir em programas de atividades físicas. Nem sempre a ciência se constitui como um campo relacional suficiente para determinar a participação e manutenção dos idosos em programas de atividades físicas, principalmente quando a sociedade coloca barreiras que impedem a visualização deste objetivo ou geram receio quanto a sua conquista. ${ }^{17,19}$ Por isso, insistimos que é imprescindível transformar o ambiente no qual estamos inseridos e construir uma nova significação sobre o próprio processo de envelhecimento, visto não apenas em suas limitações, mas acima de tudo sobre suas possibilidades. Mesmo porque, a nãotransformação do meio soa como que um incentivo para que os indivíduos também não mudem seus comportamentos.

Essa transformação é entendida aqui não apenas no sentido de uma revolução radical sobre o sistema que oprime aqueles dos quais não se podem retirar a mais-valia, como os idosos, mas também no sentido da alteração das próprias relações que se dão em ambientes criados para a prática de atividades físicas, sejam universidades, escolas, parques, praças, etc. ${ }^{20}$

Nessa perspectiva, o profissional de Educação Física não é apenas um aplicador de testes e movimentos programados, mas acima de tudo um educador com quem seus participantes podem debater e propor ideias sobre os mais diversos aspectos humanos. Devido à pluralidade do próprio saber constituinte de sua prática, é de fundamental importância que as atividades realizadas também sejam plurais nos conteúdos destinados a seus participantes, envolvendo movimentos que exijam a coordenação motora e flexibilidade; a percepção dos movimentos corporais, das limitações, mas sobretudo das potencialidades dos movimentos; a realização de um movimento de reordenação postural; atividades que envolvam relaxamento, tensão e massagens com relaxamentos; jogos cooperativos e competitivos; exercícios respiratórios; atividades aeróbias e, se possível, também atividades anaeróbias; exercícios para o estímulo da força, agilidade, equilíbrio, controle do tônus; dentre outras possibilidades do universo da Educação Física.

Tais atividades se justificam quando pensamos na velhice não apenas como um agregar de anos, mas como um tempo para experimentação de múltiplas vivências, tendo por objetivo uma vida independente e autônoma que apenas se materializa quando nossas capacidades funcionais são preservadas. Neste sentido, a importância da atividade física diversificada ganha significado por si própria. ${ }^{21}$ Além disso, as atividades físicas anteriormente citadas contribuem para a manutenção das dimensões e da própria composição corpóreo-psíquica, que em geral experimenta alterações maléficas com o decorrer dos anos, tais como: a diminuição da estatura devido à compressão vertebral, o aparecimento de doenças cardiovasculares e a redução drástica dos níveis de força muscular, a perda de memória e de massa corpórea, etc. ${ }^{22,23}$

Todas essas possíveis alterações gestadas ao longo dos anos podem ser combatidas pela prática regular e orientada de exercícios físicos diversificados, inclusive quando consideramos os problemas cognitivos, na medida em que existem dados fiáveis sobre a relação positiva entre o desenvolvimento intelectual, físico e emocional. ${ }^{24,25}$

A amplitude deste universo procedimental impede que as aulas se estabeleçam como uma rotina e possivelmente percam o estímulo para sua realização. Diversificar é uma palavra-chave quando buscamos não apenas o ingresso, mas também a permanência e sucesso dos idosos em programas de atividades físicas, já que quando aprendemos novos movimentos, estabelecemos também novas relações sociais, mais amplas e genéricas que as anteriores, passando a visualizar na diferença um elemento fundamental para a própria constituição do ser humano em questão.

\section{CONSIDERAÇÕES FINAIS}

Esperamos que este trabalho possa servir como pano de fundo para repensarmos a própria 
questão do envelhecimento e a forma como a Educação Física deve se colocar diante das problemáticas surgidas na relação, sobretudo na falta dela, entre o idoso e a sociedade da qual faz parte. Por todas estas características, a inatividade comprovada da grande maioria dos idosos não é encarada aqui como sendo apenas de sua responsabilidade, mas como produto de todo o ambiente que o rodeia, do papel social e dos estigmas derivados pela sociedade e das próprias relações estabelecidas cotidianamente que, em alguns grupos culturais, tende a isolar o idoso em ambientes cada vez mais separados do restante da população. A partir de então, a velhice passa a não ser mais encarada como sinônimo de doença ou solidão, mas como um período de desenvolvimento propício ao desenvolvimento humano rico e omnilateral.

Sabemos que os questionamentos aqui colocados estão longe de serem esgotados, mesmo porque este trabalho não possui a abrangência necessária para discutir questões mais pontuais sobre a relação entre atividade física e saúde correlacionada a aspectos sociológicos mais amplos, como a mercantilização do próprio processo de envelhecimento. Ainda assim, acreditamos poder aguçar questionamentos sobre a simples pergunta de difícil resposta: "o que é ser velho na sociedade?"

\section{REFERÊNCIAS}

1. Moscovici S. On social representations. In: Forgas JP. Social cognition. Perspectives on everyday understanding. New York: Academic Press;1981.

2. Bosi E. Memória e Sociedade: lembrança de Velhos. São Paulo: Companhia das Letras; 1995.

3. Chauí M. Uma Psicologia do Oprimido. In: Bosi E. Memória e Sociedade: lembrança de Velhos. São Paulo: Cia das Letras; 1979. 17-34.

4. Camarano AA. Muito além dos 60: os novos idosos brasileiros. Ipea: Rio de Janeiro;1999.

5. Masoro EJ. Challenges of biological aging. Nova York :Springer ;1999.

6. Vygotsky LS. Teoria e método em psicologia. São Paulo: Martins Fontes; 2004.

7. Groisman D. A velhice: entre o normal e o patológico. História, Ciências, Saúde - Manguinhos 2002 jan-abr; 9 (1):61-78.

8. Canguilhem G. O normal e o patológico. Rio de Janeiro:Forense Universitária; 1978.

9. Katz S. Disciplining old age: the formation of gerontological knowledge, Charlottesville, University Press of Virginia; 1996.

10. Haber C. Geriatrics: a specialty in search of specialists'. In: David Van Tassel et al. Old age in a burocratic society. Nova York;1986. 66-84.

11. Elias N. A solidão dos moribundos. Rio de Janeiro: Jorge Zahar; 2001.

12. Berlizi EM, Rosa PV. Estilo de Vida Ativo e Envelhecimento. In: Terra NL, Dornelles B. Envelhecimento Bem-sucedido. Porto Alegre: EDIPUCRS; 2002. 91-96.
13. Beauvoir S. A velbice. Nova Fronteira :Rio de Janeiro ; 1970.

14. Fonagy P. The theory and practice of resilience. Journal of Child Psychology and Psychiatry 1994: 35(2): 231-257.

15. Moragas R. Gerontologia Social: envelhecimento e qualidade de vida. São Paulo: Paulinas ; 1997.

16. Barry HC, Eathorne, SW. Exercise and aging. Issues for the practitioner. Medical Clinics North America; 1994; 1357-375.

17. Carmel S, Shani E. Skin cancer protective behaviors among the elderly: explaining their response to a health. Educational Gerontology; 1996. 651-669.

18. Okuma S. S. O idoso e a atividade fisica. Campinas: Papirus ; 1998.

19. Hogue C, Friese GH. The Usefulness of health risk assesssment with older adult population. In: The International Electronic Journal of Health Education. (Special issue). 2000; (3): 202-207. Disponivel em : (http://www.iejhe.siu.edu).

20. Takano $\mathrm{T}$, et. al. Urban residential environments and senior citizen's longevity in megacity areas: the importance of walkable green spaces. Journal of Epidemiology and Community Health 2002; 12 :913-8.

21. Bertchtold NC, Cotman CW. Exercise: a behavioral intervention to enhance brain health and plasticity. Trends in Neuroscience 2002;25( 6). 295-330.

22. Matsudo SM. Envelhecimento, atividade física e saúde. Rev Mineira Educ. Fís 2002; 10(1): 195-209. 
23. Gobbi S, et al. Comportamento e barreiras. Psic.: Teor. e Pesq 2008 Dez; 24(4): 451-458.

24. Benedetti TRB, et al. Atividade física e estado de saúde mental de idosos. Rev.Saúde Pública 2008 Abr ;42(2):302-307.
25. Antunes HKM, et al. Exercício físico e função cognitiva: uma revisão. RBME 2006; 12(2): 108-114.

Recebido: 13/7/2009

Revisado: 21/1/2010

Aprovado: 05/4/2010 
